\title{
O uso de haicais no ensino de química: interdisciplinaridade e ludicidade na articulação entre ciências e literatura
}

\section{Gustavo Pricinotto}

gpricinotto@utfpr.edu.br

orcid.org/0000-0001-8327-9147 Paraná (UTFPR), Campo Mourão,

Paraná, Brasil

\section{Alessandra Mayra de Lima} alessandralima@alunos.utfpr.edu.br orcid.org/0000-0001-8327-9147 Universidade Tecnológica Federal do Paraná (UTFPR), Campo Mourão, Paraná, Brasil

David Junior Falkowski junior.falkowski@hotmail.com orcid.org/0000-0001-8327-9147 Universidade Tecnológica Federal do Paraná (UTFPR), Campo Mourão,

Paraná, Brasil

\section{RESUMO}

A dificuldade com a leitura dos alunos preocupa professores de todas as disciplinas e de todos os níveis do Ensino Básico, e não passa despercebida pelos professores de Química, pois tal inconveniente afeta diretamente na compreensão dos alunos tanto para os conteúdos químicos, quanto para formação de cidadãos que visa a transformação social. O Haicai na disciplina de Química se apresenta como possibilidade de articular disciplinas tidas como dissociadas, buscando trabalhar a síntese de conteúdos na visão dos alunos, promovendo a escrita de maneira leve, porém, carregada de significados que foram analisados neste trabalho. Existem diferentes maneiras de promover leitura e escrita dentro de uma sala de aula, e com esse trabalho é possível observar que essas duas ferramentas são fundamentais para o processo de ensino/aprendizagem, partindo de uma aula contextualizada de Química e atingindo poemas que falam sobre Química e conscientização.

PALAVRAS-CHAVE: Leitura. Haicai. Ensino. Química. Criatividade. 


\section{INTRODUÇÃO}

O presente artigo tem por objetivo o estudo e reflexão do uso da escrita no processo de catarse para o Ensino de Química, em que o estudante busca apresentar sua "realidade", que em momento sequencial será rearticulado a outras possibilidades sob um viés histórico e social de construção do conhecimento, perpassando deste modo pela síntese mental do aluno.

O estudo se deu com alunos do segundo ano do ensino médio, na disciplina de Química de um colégio localizado na região noroeste do Paraná. O que motivou este projeto foram as grandes dificuldades apresentadas pelos estudantes, inicialmente na interpretação e compreensão de textos, e posteriormente, o efeito destes sob o ensino de Química, leitura, escrita e na criatividade, o que deu espaço para uma articulação e interdisciplinaridade, principalmente, entre Ciências e Língua Portuguesa. Neste sentido buscamos em nossa atividade uma articulação com gêneros discursivos e o Ensino de Química, partindo da confecção de poemas que aproximam e rearticulam a criatividade e a expressão do conhecimento desenvolvido, em 3 versos, ou seja, em poucas palavras. Leva-se em consideração o contexto a ser aplicado o conteúdo e as dimensões que foram trabalhadas em sala, visando uma aula baseada na formação de um aluno crítico.

É notória a dificuldade apresentada pelos estudantes no que se relaciona com a leitura, os alunos possuem dificuldade ao ler, obedecer a acentuação e pontuação, o que torna preocupante a continuação do ensino de qualquer conteúdo. Tendo como ponto de partida essa dificuldade, torna-se de extrema urgência e importante uma rearticulação de gêneros textuais e conhecimento científico, pois por demonstrarem dificuldades com a língua materna, eles não entendem o que estão lendo, partilhando assim, de dificuldades para a compreensão de outras disciplinas, como Matemática, Química ou Biologia.

Tendo como objetivo das escolas a formação de estudantes críticos, capazes de realizarem a transformação que querem no mundo, temos de primeiramente repensar nosso papel enquanto professores de disciplinas específicas das Ciências (Química, Física, Biologia) e nossa relação com a escrita e a interpretação de texto, pois, antes de uma compreensão aprofundada de conceitos científicos, precisamos apresentar aos nossos estudantes, conhecimentos básicos para o exercícios da cidadania, entre eles a língua portuguesa. Para tornar-se cidadão, é fundamental que o aluno saiba se posicionar frente a um texto de forma crítica, sabendo rearticular as informações que a ele são apresentadas, transformando-as em conhecimento. O domínio da leitura na disciplina de Química é tão primordial quanto em qualquer outra disciplina, isso pois temos uma quantidade simbólica textual significativa, com diversidade de sinais técnicos particularmente científicos, que quando não compreendidos corretamente fazem com que os alunos percam o sentido da explicação, mesmo que esta esteja descrita textualmente. (WENZEL, 2018)

Sabemos que a leitura e a escrita são ferramentas de ensino que devem ser utilizadas pelos professores, porém muitas vezes os próprios docentes não têm o hábito de ler ou não veem sentido da leitura por nunca terem ouvido falar sobre esse método dentro da graduação, em articulação com as disciplinas ditas científicas (duras), não tendo acesso nem ao termo Literatura de Divulgação 
Química tiverem acesso a esse tipo de literatura e conhecerem o potencial da leitura provavelmente irão começar a difundir o hábito de confrontar ideias com o texto (FLOR, 2011).

Para além da formação ultrapassada e limitada de muitos profissionais das áreas de Ciências, há uma grande dificuldade por parte de toda a escola em instigar e interessar o aluno na cultura literária, alguns professores tentam obrigá-los a ler livros e outros tentam promover a leitura por meio de grupos literários, mas em ambas atividades se encontram percalços, assim como a dificuldade em encontrar livros dentro das escolas ou e-books gratuitos, mas o obstáculo mais conflituoso, muitas vezes é a falta de interesse por parte dos alunos quanto a leitura, desse modo, é necessário encontrar maneiras e assuntos que chamem a atenção dos alunos. Tendo como pano de fundo essa preocupação, pareceu-nos interessante sugerir a utilização dos Haicais que trabalham a escrita de maneira poética, profunda, criativa e curta. Mesmo que não habite o contexto químico de forma explicita - que é o foco do estudo - há muitas obras brasileiras que são constituídas por trocadilhos e poesia e podem ser indicadas para o Ensino Médio, que trabalham com as palavras escrevendo o mínimo - visto que o haicai é um poema curto - para que se sinta ao máximo as emoções, sendo a escrita do suficiente para que se compreenda o que está escrito e se entenda o que diz e o que não diz, e isso constitui o saber ler (MARAFRON, 2014).

Os sentimentos japoneses descritos em poemas e Haicais, assim como a cultura passaram a ser conhecidos na Europa em 1904, com as viagens de Chamberlain. Quanto aos haicais na composição conhecida hoje, ganharam cena com sua primeira publicação em 1916 na França, intitulado Cent visions de guerre, por Julien Vocance, de pseudônimo Joseph Seguin. Vocance trouxe uma nova força aos poemas, que foram adaptados a língua portuguesa por Guilherme de Almeida em 1930. As adaptações mantiveram dois aspectos originais: a distribuição das palavras em três segmentos, aos quais chamamos de versos, e a composição por justaposição de duas frases, tópico/comentário (FRANCHETTI, 2008). Havendo ainda a distribuição de dezessete sílabas poéticas, distribuídas em cinco silabas no primeiro verso, sete no segundo e cinco no terceiro. O efeito rítmico é formado pelas rimas que unem o primeiro e terceiro verso, e uma rima interna no segundo, que ocupa a segunda e última sílaba (FIOROTTI, 2016).

O objetivo deste trabalho, portanto, é a articulação entre a escrita (Língua Portuguesa) e os conceitos científicos (Química), visando apresentar a utilização de poemas curtos dentro de sala de aula como potenciais recursos de ensino e aprendizagem. A composição de poemas depende da criatividade, da compressão dos conteúdos debatidos em sala de aula e da percepção dos alunos quanto aos contextos, além da escrita potencializada pelo conhecimento da língua materna. A dificuldade com a escrita e a leitura reverberam na compreensão dos textos, que por sua vez atinge o entendimento do aluno quanto a disciplina, neste sentido, acreditamos que a grande potencialidade deste trabalho, ao buscar a interdisciplinaridade e articulação de disciplinas "científicas e não-científicas", torna-se um passo importante para superar a lacuna deixada ao longo do Ensino Básico apresentada acima. 


\section{JUSTIFICATIVA}

A inspiração para o desenvolvimento deste trabalho ocorreu durante o desenvolvimento do Estágio Curricular Supervisionado do curso de Licenciatura em Química da Universidade Tecnológica Federal do Paraná, campus Campo Mourão, quando durante o período de regência nos deparamos com a dificuldade que os alunos do 2ㅇ ano do Ensino Médio apresentavam quanto a habilidade de leitura e interpretação de textos iniciais da disciplina. A situação chamou a atenção por ser a leitura um ponto excepcionalmente importante no ensino de qualquer disciplina, pois se essa dificuldade é encarada por eles significa que há uma impossibilidade do aluno/leitor conversar com o texto, o que pode causar a incompreensão, não distinguindo o que o texto tem a passar como aborda Marafron e Massagli (2014).

Articulando essa dificuldade exibida pelos estudantes com a proposta apresentada pelo Projeto Político Pedagógico do Colégio, em que neste consta que se espera a superação do senso comum e a busca pela compreensão do mundo, formando cidadãos capazes de tomar decisões condizentes com o ensino conceitual científico estruturado, além da transformação social, "objetiva-se formar cidadão consciente e participativo, buscando prepará-lo para ser um sujeito transformador da sua própria realidade, fazendo acontecer um novo momento histórico" (PPP, 2018, p.06).

Torna-se fundamental, para que a escola seja capaz de atingir este objetivo, um trabalho articulado entre gestão, professores e demais participantes do processo de ensino, principalmente no que tange ao ensino interdisciplinar e cidadão, desde os responsáveis pelos serviços técnicos, administrativos, até a equipe da gerência, aos pedagogos, professores e alunos, pois isso faz com que o barco se mova em um sentido único (VASCONCELLOS, 2012).

Segundo Junior (2010), diferente do que se pode pensar na dissociação entre o Ensino de química e a literatura/escrita, "o professor de Química também deve ser visto como um professor de leitura". Nesta direção, trabalhar a leitura em mais de uma disciplina é uma maneira de estimular o aluno a ler e buscar conhecimentos informais, tornando a contextualização mais realista dentro dos conteúdos. Com isso, não buscamos apontar esse ou aquele como possíveis responsáveis, aplicando medidas punitivas ou premiações, mas sim ampliar nossas dimensões enquanto professores de Ciências, buscando dar o ponta pé inicial para mudanças e possivelmente encontrarmos e desenvolvermos dentro da disciplina de Química possíveis habilidades, até então vista como isoladas desta Ciência dogmatizada, rearticulando estudantes à química por meio de poesia.

No âmbito da interdisciplinaridade e articulação entre Ciências e Língua Portuguesa, os trabalhos encontrados na literatura abordam, na maioria dos casos, a Literatura Científica no âmbito da graduação. Ainda partilhando das ideias de Junior (2010), evidencia-se a lacuna presente nos trabalhos que associam leitura e escrita com o ensino de Química, segundo sua pesquisa em periódicos especializados da área de Educação em Química e/ou Ciências no Brasil. Outros trabalhos ainda são relacionados aos desenvolvimentos de oficinas sobre o tema ou a leitura mas não exploram a escrita de poemas haicais, o que torna este trabalho potencialmente diferenciado dos demais. 
Por esses motivos a proposta de trabalhar Haicais no Ensino Médio pode se mostrar além de inspiradora, também como uma forma de avaliação formativa, como apresentamos neste trabalho, capaz de promover ao aluno gosto pela literatura de uma maneira diferente e divertida, possibilitando assim uma reconstrução histórica dos conhecimentos envolvidos no ensino de Química. Dessa maneira há a necessidade de uma aula interdisciplinar, que proporcione posteriormente ao aluno a capacidade de sintetizar suas próprias ideias e com suas palavras colocar em prática a Literatura Científica.

\section{HISTÓRIA DA DISCIPLINA DE QUÍMICA NA EDUCAÇÃO}

A disciplina de Química e o seu ensinar apresenta dificuldades devido a diversificados fatores, perpassando pelo desinteresse dos estudantes, por ser muitas vezes advertida historicamente e popularmente, como afirma Torriceli (2007), uma disciplina centrada no uso de fórmulas, cálculos e memorização excessiva. E ainda, como afirmam Sá e Santos (2011), muitas vezes pela falta de motivação pela carreira docente e consequentemente uma carência de professores, principalmente nas áreas de Ciências Exatas de Química e Física.

Este Segundo ponto chama a atenção pois, muitos dos que buscam os cursos de Licenciatura em Química para tornarem-se professores, acabam se deparando com cursos fundamentados em uma grade de bacharelado, tornando a opção pelo curso uma medida provisória e transitiva (TARTUCE, 2010), levando muitos destes a transitarem por empresas farmacêuticas e outras da área industrial. Sendo assim, acreditamos que o principal problema encontrado seja a falta de professores de Química adequadamente preparados e interessados para lecionar em tal área, pois quando veem a profissão de professor como algo transitivo, afetam diretamente a formação dos alunos do Ensino Médio.

A disciplina Química foi implantada no currículo escolar brasileiro em 1862, ganhando posição obrigatória e objetiva nos currículos em 1931, visando a apropriação de conhecimentos específicos. Aos professores, cabia oferecer um conteúdo mecanizado e descontextualizado, fortalecendo a ideia de uma Ciência pura e dogmatizada, diferentemente do que potencialmente acreditamos no Ensino atual, em que cabe ao professor desenvolver um conteúdo que desperte o interesse científico nos alunos enfatizando a relação da química com a vida cotidiana.

Posteriormente, passando pela ditatura que não representou avanços na área da Educação Química, retendo o conhecimento científico para uma minoria, em 1998 os Parâmetros Curriculares Nacionais, baseados em medidas neoliberais e influenciados por Organismos Multilaterais (Banco Mundial, A Organização das Nações Unidas para a Educação, a Ciência e a Cultura - UNESCO, Fundo das Nações Unidas para a Infância - UNICEF, Comissão Econômica para a América Latina e o Caribe - CEPAL e o Programa das Nações Unidas para o Desenvolvimento - PNUD), representaram um passo atrás no ensino (MAZZEU, 2008), estabelecendo uma retomada do ensino descontextualizado e de memorização nos mais profundos níveis teóricos (racionalização conceitual sobre os fenômenos químicos) e representacional (simbologia química), com temáticas de caráter generalista, uma vez que não permitiam interconexões entre os níveis científicos, com defasagens 
expostas nos PCN que buscam resolução nas Diretrizes Curriculares Estadual (DCE) do estado do Paraná no ano de 2008 (PARANÁ, 2008).

Em 2016, após a mudança de governo, acontece um dos maiores cortes orçamentários para a educação brasileira, indo contrário a DCE (BRASIL, 1996). A Medida Provisória 746 de 2016 (MP - no 746/16), instituindo a Política de Fomento à Implementação de Escolas de Ensino Médio em Tempo Integral (EMTI) e a Base Nacional Comum Curricular (BNCC), medidas entendidas como sendo potencialmente discriminatórias, com grande potencialidade para acentuar ainda mais a dualidade educacional, condicionando o ensino médio a uma base curricular minimalista e à relação com o empresariado para a oferta do ensino técnico profissional (BRASIL, 2016). Essa Medida Provisória 746 tornou-se Lei em 2017 (Lei n. 13.41/2017) (BRASIL, 2017b), legitimando ainda mais os prejuízos dessa medida lesiva para a educação, possibilitando o ensino a distância e enfraquecimento na formação docente com o notório saber, inclusive na disciplina de Química, afastando possíveis interessados em sair do ensino médio e ingressar posteriormente na formação docente e a presença de profissionais não capacitados sendo admitidos em sala de aula.

Toda a história que envolve a disciplina de Química, tem reflexo na atualidade, de acordo com dados divulgados pelo Instituto Nacional de Estudos e Pesquisas Educacionais - INEP em 2017, apenas 61\% dos professores que atuam na disciplina de Química no Brasil, por exemplo, são licenciados (BRASIL, 2017a). Esses dados estão relacionados diretamente, e não somente, a visão deturpada que se da disciplina de Química, exaltando uma dificuldade na mesma, superior a real, diminuindo o número de pessoas interessadas em ingressarem no percurso para tal profissão, sem política de ensino capazes de reverter o quadro de descaso com o ensino básico se tornou difícil prever o futuro desta ou de qualquer outra disciplina.

\section{DESMISTIFICAÇÃO DA CIÊNCIA}

Em nosso trabalho, buscamos compreender as ciências de forma plural e não dogmatizada, desmitificando a Ciência ${ }^{1}$ que ainda é vista como aquela que ajuda e traz verdades. O sentido da palavra desmistificar é trazer a verdadeira face da ciência, é apresentar as químicas e as ciências de forma desdogmatizada, não prontas, acabadas, inquestionáveis, neutras e imparciais, ambas estão em constante transformação em função das necessidades, principalmente as necessidades da sociedade e tecnologia.

Não existe a pessoa certa para falar de ciências, pois as ciências acontecem e evoluem por cada um de nós e para todos nós, diante de diversificados e atravessados interesses sociais, ambientais, econômicos, políticos, articulados as necessidades e as curiosidades que movem as buscas por conhecimento. Elaborada e desenvolvida por todos, as ciências tornam-se passíveis de falhas e erros, sendo impossível separá-las de suas articulações de bastidores, havendo constante interferência social sobre qualquer aspecto científico. Conhecendo todos esses efeitos sociais cabe ao professor apresentar essa outra face do conhecimento científico, reconstruindo junto com o aluno os conceitos, demonstrando suas fragilidades, histórias e articulações nas mais distintas faces, e não somente a dogmatizada historicamente pelo Ensino de Ciências. 
Diferentemente do que dizem os defensores da Ciência enquanto verdade e dogma, acreditamos que dentro ou fora da sala de aula nada pode ser aceito pelo simples fato de ser apresentado por um membro representante da Ciência, ou aceitarmos pagar mais caro em um produto que se diz cientificamente testado sem saber o que isso significa. É neste sentido que compreendemos que a perspectiva da prática social deve ser colocada como ponto de partida e de chegada da prática educativa, rearticulando os contextos, os momentos históricos, sociais e econômicos da produção científica. Nasce a necessidade de um método pedagógico que parta da prática social, onde professor e aluno se encontram igualmente inseridos ocupando, porém, posições distintas, condição para que travem uma relação fecunda na compreensão e encaminhamento da solução dos problemas postos pelo contexto sócio-histórico (PARANÁ, 2008).

O DCE de Química do estado do Paraná traz a importância de se trabalhar de forma crítica algo que é desenvolvido em cima de uma base social. A Química é construída diariamente sobre os impulsos e necessidades das empresas, onde pessoas leigas desempenham funções e não sabem ao certo com que tipo de material estão trabalhando, onde a mesma fábrica que cria fármacos que salvam vidas, criam superbactérias, aí está a importância de se compreender o contexto em que se produz e desenvolve ciências. Cabe então aos profissionais do ensino falar sobre toxicidade, cálculos, balanceamento de reação, nomenclatura, estados da matérias, formulas moleculares, estruturas atômicas, radiatividade, gases inertes e tantos outros conceitos de forma contextualizada, falando também sobre remédios como a Talidomida, o uso da Maconha para síntese medicinal de CBD e THC, utilizados no tratamento de pessoas com esquizofrenia, mal de Parkinson, esclerose múltipla, epilepsia e outras, o uso da radioatividade nas Usinas Nucleares e das Bombas nucleares.

Cabe ao professor tratar de temas que muitas vezes são silenciados nas salas de aula, por se tratar de questões "políticas", e sendo assim, falar de alimentos transgênicos e da falta dos mantimentos e de tantos outros conceitos que são considerados polêmicos, pois é nesse tipo de conversa e debate que o conhecimento cientifico se estabelece e acontece sua desmistificação, as pessoas deixam de ter medo de usar produtos químicos e os veem como criação para solução das necessidades de cada pessoa no dia-a-dia (PARANÁ, 2008). Cabe ao professor de Química segundo o DCE-Química:

[...] subsidiar reflexões sobre o ensino de Química, possibilitando novos direcionamentos e abordagens da prática docente no processo ensinoaprendizagem, para formar um aluno que se aproprie dos conhecimentos químicos e seja capaz de refletir criticamente sobre o meio em que está inserido. (PARANÁ, 2008, p. 50).

Lemos 2013, ao associar Foucault à formação docente fala sobre o espaço ocupado pelos professores no mundo atual, com toda a tecnologia de informação e comunicação. Não basta formar apenas professores que dominem o conteúdo químico, é necessário a formação de uma pessoa que seja capaz de promover a mudança, que seja causador de mudanças na educação, pensando

que existem homogeneidades e heterogeneidades, que se entrecruzam, produzindo assim as relações e interdependências nas assimilações dos saberes e produção do conhecimento (LEMOS, 2013, p. 50). 
Trabalhar este rearticular interdisciplinar de conhecimentos múltiplos, é dar possiblidades de os estudantes decidirem o que pretendem conhecer e como, abrindo possibilidades democráticas de uma visão real do mundo. Para que possamos atingir este objetivo, é necessária a quebra de paradigmas e a busca pela pluralidade de conhecimento, administrando uma prática pedagógica que não se perpetue no simples didático, mas que seja renovada e atual, que seja capaz de se reinventar de acordo com as necessidades dos alunos e das escolas, ultrapassando as barreiras institucionais, visto que é primordial que o aluno leve para fora da sala de aula a utilização dos conhecimentos e que consiga levar a diante os ensinamentos, externalizando para a comunidade e para a família (LEMOS, 2013).

É nessa possibilidade de democratização dos conhecimentos, de pluralidade do conhecer, que acreditamos ter potencialidade a articulação entre literatura e ciências, compreendendo essa manifestação como uma arte crítica do ser cidadão, neste sentido faz-se necessária uma aula por meio da dialética, com debate e conversação, pois, deste modo, a necessidade de inquerir e questionar as vertentes científicas e os motivos pelos quais os conhecimentos se produzem torna-se habitual e constantemente utilizado pelos estudantes.

\section{GENEROS TEXTUAIS E ENSINO DE QUÍMICA}

Na busca pela democratização do conhecimento e pluralização das ciências, por meio de um ensino que se distancie dos dogmas e se aproxime cada vez mais das particularidades e contextos dos estudantes, acreditamos que diversos gêneros textuais podem contribuir para o Ensino de Química. Alguns exemplos já são vistos na área, como por exemplo a utilização de textos jornalísticos, poesias e outros. Para Moreira (2005), a

\footnotetext{
“Ciência e poesia pertencem à busca imaginativa humana, embora ligadas a domínios diferentes de conhecimento e valor. A visão poética cresce da intuição criativa, da experiencia humana singular e do conhecimento do poeta. A ciência gira em torno do fazer concreto, da construção de imagens comuns da experiencia compartilhada e da edificação do conhecimento coletivo sobre o mundo circundante" (p.17).
}

Partindo dessa articulação entre a concretude da Ciência e da criatividade da poesia, produzimos ciências plurais e heterogêneas, que reassociem o contexto dos estudantes e as possibilidades distintas de se pensar ciências. Segundo os próprios Parâmetros Curriculares Nacionais (PCN) (Brasil, 2000) existe uma demanda necessária de estimularmos nossos estudantes a escrita, ampliando assim a possibilidade de participação crítica social dos educandos no exercício da cidadania individual e coletiva.

Godinho (2008) ao tratar de gêneros textuais para o processo de ensino e aprendizagem, afirma que poemas

\footnotetext{
"podem ter formas variadas, podem usar palavras simples, do cotidiano ou rebuscadas, podem apresentar ou não rimas, podem ser ou não divididos em estrofes, podem apresentar o mais variado número de versos e/ou número de sílabas poéticas, pode ter ou não pontuação, entre outros. Foi possível desconstruir em alguns aspectos aquela visão estereotipada que o aluno apresentava." (p.3)
} 
Diante dessa afirmativa, acreditamos na potencialidade de se pensar os haicais como, mesmo diante das dificuldades apresentadas pelos estudantes com a escrita, possibilidade de os estudantes desconstruírem e rearticularem suas formas de conhecer e sintetizar o mundo. Diante disso, apresentamos, maneiras de abordar o ensino de Química e de seus conhecimentos articulado a potencialidade do uso dos haicais como gênero textual para a interdisciplinaridade.

\section{MUDANÇAS POSSÍVEIS NA ABORDAGEM DE CONTEÚDOS QUÍMICOS}

As mudanças são necessárias para além do ensino na graduação, devem ser estendidas para o Ensino Básico, pois existem diversas possibilidades de se lidar com os conteúdos (de Ciências, Química e outras) de maneira que esses sejam inspiradores aos olhos de quem está prestes a compreendê-los. Para que essas mudanças sejam possíveis é necessário que os professores tomem um importante papel, este conhecido e talvez como o mais alcantilado, que é trabalhar com criatividade, pois o que se repete tantas vezes para um professor pode ser a primeira e única vez que o aluno terá contato (PONTES, 2008).

Compreendemos também que muitas modificações nas escolas são necessárias para alcançar o que os alunos esperam, e para que os professores possam se atentar a tal criatividade. Atualmente os alunos sabem onde encontrar informações, eles possuem os mais rápidos pontos de acesso, apresentam-se a frente da escola e de diversos professores quando o tema é tecnologia, e isso nos deve causar a seguinte inquietação que nos faz refletir: onde ficou estacionada a escola quando todo o cenário analógico evoluiu? Como pontuam os autores Oliva e Santos (2016), a escola não evoluiu junto com os alunos e atualmente ela não corresponde suas expectativas, ficando atrás de aparelhos celulares no quesito chamar a atenção do aluno.

Neste cenário, as principais mudanças para a Química são descritas na área da experimentação, aplicação prática, seja em sala ou em laboratório, estes últimos, muitas vezes transformados em depósitos, almoxarifados e outras tantas finalidades, pois, de fato essa medida visa modificações na rotina de ensino da atual metodologia, porém ela desacompanhada de discussão e debate não é o suficiente para manter o aluno interessado, talvez suficiente em um primeiro momento. Diante deste cenário de busca por mudanças, cabe frisar que independente do recurso ou metodologia, temos de acordar que é na práxis que podemos compreender o processo de ensinar a Química, não sendo suficiente a apresentação da mesma de forma desarticulada entre teoria e prática, de modo que a leitura não supre a prática, ela apenas irá agregar tanto para as percepções do aluno, sua capacidade de sintetizar uma ideia e para a transformação social desejada (CALDEIRA, 2013).

Neste papel de superar a dissociabilidade muitas vezes imposta pelas atividades práticas, buscando articular conhecimento científico, teórico e prático, diante de um âmbito lúdico, o Haicai assume um compromisso criativo dentro do Ensino de Química, uma característica que contribui para a formação dos alunos e professores, visando a contextualização e interdisciplinaridade, não substituindo a prática experimental, mas como uma alternativa do aluno expor sua opinião quanto ao que aprendeu ao decorrer do conteúdo Químico, e principalmente, 
contribuindo como possibilidade de superação do distanciamento entre teoria e prática.

Neste percurso, buscamos no presente trabalho analisar o conteúdo presente na produção de haicais de estudantes da educação básica, confeccionados individualmente. A atividade de confecção de gênero textual desenvolveu-se posterior a uma aula introdutória sobre os conteúdos de Entalpia de ligações e lei de Hess, na qual desenvolvemos uma contextualização e aproximação da realidade dos estudantes através de reflexões sobre a importância de conhecer o efeito estufa na contemporaneidade, visto muitas vezes somente sob um ponto de vista destrutivo, de modo dicotômico e inquestionável, na sequência, falou-se sobre a composição da camada de ozônio de modo articulado a proposta de produção de haicais, explicando e apresentando exemplos aos estudantes de como são desenvolvidos os textos deste gênero.

A análise qualitativa, sob um viés da análise de conteúdo, nesse caso avalia uma pequena parte da síntese do aluno sobre um conteúdo extenso, não exime a necessidade de atividades que calculem a entalpia, mas traz à tona o que o aluno compreendeu sobre a aula, além dos cálculos, distanciando-se de uma atividade que vise ser diagnóstica ou somativa, buscando aproximar-se de uma avaliação formativa em que durante o processo de construção do conhecimento "o professor possa ajustá-lo às características dos estudantes a que se dirige. Suas funções são as de orientar, apoiar, reforçar e corrigir" (GIL, 2006, p. 247), tendo um viés de compreensão das formas e sequências de aprendizagem dos estudantes. Neste sentido, a análise qualitativa deve levar em consideração todos os dados coletados, não deixando de lado nem mesmo os dados implícitos como descreve Ludke e André (2012), nenhum dado pode ficar de fora da análise, do mesmo modo que como pesquisador não podemos demostrar preferências com base nos resultados.

Neste contexto a atividade foi realizada em uma turma de 20 ano do Ensino Médio de um colégio da região noroeste do Estado do Paraná, com um público de 17 estudantes presentes, dos quais somente 15 alunos concluíram e entregaram o haicai. A partir desses, realizamos uma categorização, que será compreendida neste trabalho como apresentado por Krippendorf (1990, p.30):

Em qualquer mensagem escrita, simultaneamente, podem ser computadas letras, palavras e orações; podem categorizar-se as frases, descrever a estrutura lógica das expressões, verificar as associações, denotações, conotações e também podem formular-se interpretações psiquiátricas, sociológicas ou políticas.

Deste modo, buscamos realizar associações entre as produções, buscando afinidades e diferenças entre os produtos, seja nas questões de gênero textual ou de conteúdos químicos anteriormente discutidos, sendo assim, os alunos que alcançaram o objetivo quanto ao aprendizado de conteúdos químicos e sua relação com o cotidiano foram computados em uma categoria, os que parcialmente atingiram este objetivo em outra, e por fim, outra categoria foi referente aos estudantes que não atingiram os requisitos de uma estrutura de um haicai, por exemplo, não cumprir com o número específicos de versos.

Os haicais recebidos foram categorizados, essa categorização se deu com os 
objetivo e aos que não correspondem a Haicais, sendo o objetivo inicial e principal, a capacidade de articular gênero textual, conteúdos científicos de química e contextualização. Os resultados estão dispostos na tabela 1.

Tabela 1 - Categorização dos Haicais

\begin{tabular}{cc} 
Categoria & Quantidade de alunos \\
Haicais que alcançaram o objetivo proposto & 8 \\
\hline Haicais que que não alcançaram o objetivo proposto & 6 \\
\hline Atividades que não correspondem a Haicais & 1 \\
\hline Total & 15 \\
\hline
\end{tabular}

Fonte: Autoria Própria (2018).

Além dos Haicais alguns alunos optaram ainda por complementarem os haicais confeccionando desenhos, algo que durante a atividade foi adaptado perante a dificuldade dos estudantes com a escrita, e como apresentado anteriormente, todos os pontos foram levados em consideração. Diante das primeiras atividades apresentadas, os haicais foram categorizados novamente. Quanto a utilização ou não de desenhos complementares, e quanto aos erros ortográficos e de conteúdo químico envolvido, e os resultados, dispusemos em uma segunda tabela.

Tabela 2 - Categorização das sutilezas presentes nos Haicais

\begin{tabular}{cc} 
Categoria & Quantidade de alunos \\
Haicais que continham desenho & 3 \\
\hline Haicais que continham erros ortográficos & 4 \\
\hline Haicais que continham erros de conteúdo & 7 \\
\hline Total & $\mathbf{1 4}$ \\
\hline
\end{tabular}

Fonte: Autoria Própria (2018).

Das atividades que representaram corretamente haicais, as quatro que apresentaram erros ortográficos também fugiram do tema ou escreveram informações que não condiziam com que havia sido estudo, como por exemplo dizendo que a radiação contribui para a destruição da camada de ozônio (Fig. 1), quando na verdade ela a mantém formada. Outro ponto que chamou atenção foi o fato de terem 3 atividades com desenhos e nenhuma delas apresentar erros ortográficos, o que colabora com a ideia de prática docente reflexiva, na qual modificou-se a proposta para atender as necessidades dos estudantes, evidenciar outras habilidades dos discentes, que não somente as contas, números, equações e formulas, pois, assim como a escrita pode ser a potencialidade dos estudantes, também devemos dar crédito a outras habilidades. 
Figura 1 - Haicais. a) Com erros de ortografia e conteúdo; b) Criativo e com desenho

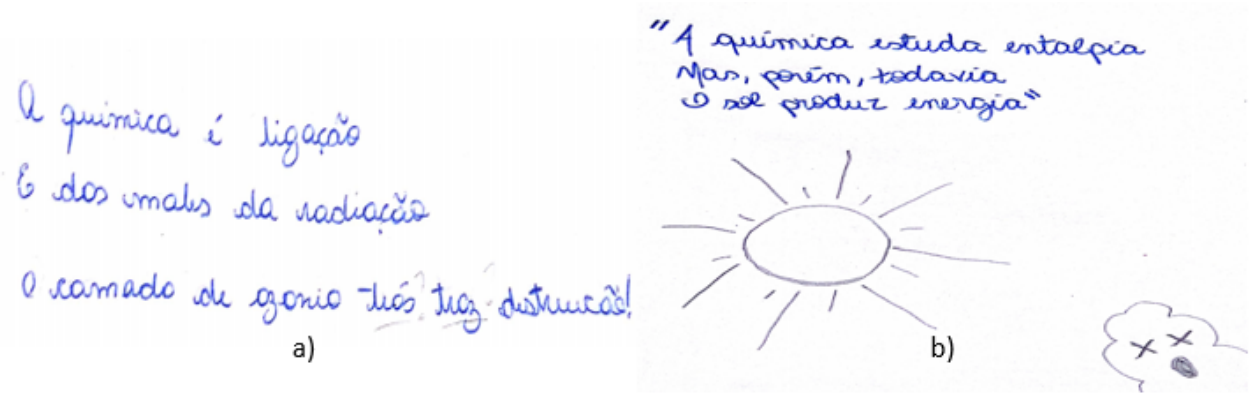

Fonte: Autoria própria (2018).

Os Haicais possibilitam aos alunos uma abstração superior à de uma aula expositiva não dialogada, pois os faz pensar e refletir sobre o que foi discutido, já que ao buscarem articular conhecimento químico, gênero textual e contexto, os estudantes são postos diante de situações de tomada de decisão. Muitas vezes, professores optam por textos grandes e que não desafiam o aluno na busca por referências e a realização de críticas sob os mesmos, distanciando-os da possibilidade de uma formação cidadã. Talvez os alunos se sintam confortáveis em escrever um texto ou resumo, mas esse conforto muitas vezes omite outras potencialidades e habilidades dos estudantes, não possibilitando a apresentação da criatividade no desenvolvimento de outras potencialidades. O Haicai apresentado na figura 2, chama a atenção quanto a criticidade do estudante para apresentar a influência maléfica de pequenas quantidades de gases CFC emitidos, sendo esses capazes de causar grandes danos a camada de ozônio.

Figura 2 - Haicais criativo

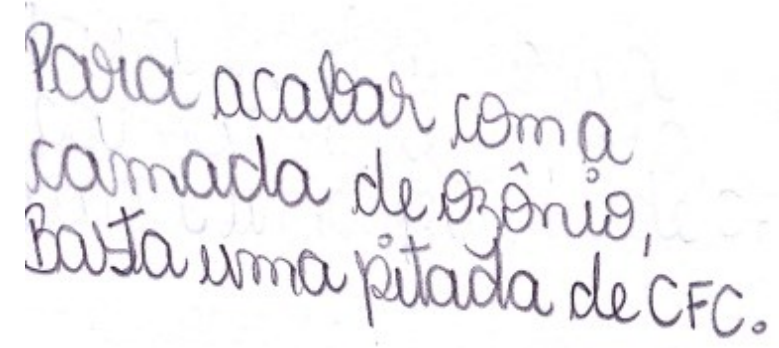

Fonte: Autoria própria (2018).

Outros trabalharam as palavras para um lado mais sensível, buscando expressar algo além da Camada de Ozônio (Fig. 3). Mesmo que fugindo do tema principal o aluno se refere a diversão, uma expressão que segundo eles no começo não era relacionável, e isso não deve ser qualificado como errado, já que sofremos todos os tipos de reações em nosso corpo a cada segundo e a variação de energia é fundamental nesse sistema. 
Figura 3 - Uma expressão mais sentimental

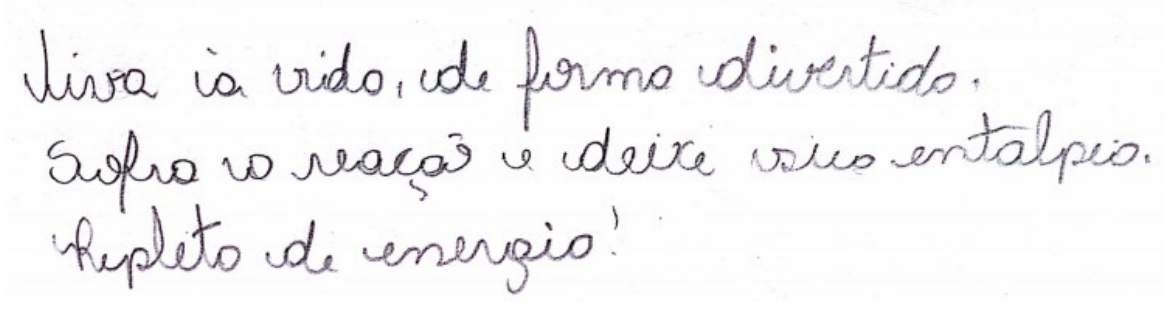

Fonte: Autoria própria (2018).

Durante a problematização e contextualização do conteúdo, os alunos demonstraram grande perplexidade quanto a fala sobre o efeito estufa. Nesse momento fez-se necessária a retomada de conteúdo, buscando sanar dúvidas de pré-requisitos que os estudantes deveriam compreender. O que nos provocava ali, era que não poderíamos deixar os estudantes saírem de sala de aula com um ponto de vista dicotômico e acrítico, ou seja, como deixar que eles saíssem da aula acreditando que o efeito estufa terminalmente iria acabar com o planeta quando este é fundamental para aquecer a Terra?

Do mesmo modo o ozônio fora da estratosfera representa um risco a todos os habitantes terrestres, logo os raios em meio as tempestades têm o papel de liberar radicais que reagem com o ozônio. É nesse tipo de polarização de posicionamentos que os estudantes devem ser capacitados para se posicionarem e tomar decisões. Sendo assim, o que buscamos fazer com que compreendessem, é que o problema está em que quando liberamos grandes quantidades de CFC afetamos tanto a Camada de ozônio que em certos lugares do globo terrestre ela deixa de existir.

Como os alunos apresentam dificuldades com a leitura e a escrita, esta proposta se mostra como um passo para trazer poemas e hábitos de leitura para dentro da aula de Química. Como pontua Marafron e Massagli (2014), ler não certifica que o leitor terá facilidade com a escrita, mas ler e atuar na escrita são maneiras de treinar e obter perícia nessa prática, e isso, enquanto professores de química, se torna ainda mais válido, ao articularmos leitura, escrita e conhecimentos científicos. Vale ressaltar que todos na escola são responsáveis pela formação dos alunos para cidadania, e que se os objetivos estão estabelecidos no Projeto Político Pedagógico, significa que são a expressão do desejo da comunidade, de que todos que saem da escola tenham em mente a transformação social por acontecer.

Levar o lúdico para dentro da sala, em uma articulação científica química, linguística e literária, é tão importante quanto o conteúdo em si, pois supera a possibilidade dicotômica e dissociada de teoria e prática, possibilitando a práxis docente. Apresentamos deste modo, pois torna-se obsoleto a sobreposição de conteúdos desconectados, desvinculados da realidade e superfaturados de fórmulas e equações, em um mundo em que os estudantes têm em mãos o celular a qualquer momento, dando acesso a toda a gigantesca gama de conteúdo das disciplinas. O lúdico é buscar articular as teorias que estão "dadas" na internet, por meio de um posicionamento crítico, é a busca por associações que ainda não ocorreram, é procurar criar a Literatura Científica dentro da sala de aula, mesmo que ela pareça não ser tão forte fora dela. Essa rearticulação de disciplinas e a forma de contextualização devem partir de diversos elementos, sujeitos e fatores, 
sejam eles escola, professores, estudantes, buscando sempre uma inovação e rearticulação dos conhecimentos distribuídos em diversos materiais. Essa é a evolução que a escola precisa, além de reproduzir, necessitamos recriar.

\section{CONSIDERAÇÕES FINAIS}

Não é fácil trazer para dentro de sala ideias inovadoras, também não é fácil fazer com que alunos sintam vontade de ler e escrever, mas tentar se manter firme nessas ideias é necessário para que possamos superar os problemas apresentados no início do trabalho, tanto na formação inicial e continuada, assim como na prática docente. Como dito, a história da disciplina de Química evidencia que a mesma passa e passou por percalços diversos, sendo muitas vezes considerada como complexa e impossível de ser compreendida, baseada em tabelas, equações, fórmulas e cálculos, cabe aos professores mudarem essa história, e não só a estes. O lúdico vai de jogos a músicas, de encenações a poemas, porém, é facilmente descartado por pedagogias tradicionais, que creem que os alunos não sejam capazes de receber uma transmissão de conhecimento, quando o próprio profissional se mostra desmotivado para o fazer.

Este trabalho teve como objetivo agir na contramão de uma aula expositiva não dialogada, desarticulada do contexto dos estudantes e multidisciplinar, apresentando por meio de um tema relacionado ao efeito estufa, conteúdos químicos contextualizados e provocando a curiosidade dos alunos a partir da articulação de poemas, propondo a estes que desenvolvessem seus próprios poemas Haicais, que englobasse conteúdo, contexto e escrita literária com a Química. Enquanto alguns buscaram conceitos outros buscaram conscientização, uns tiveram erros de ortografia e outros de conteúdo no mesmo tempo em que distintos além de escrever desenharam, mas na grande maioria dos produtos, pudemos observar a busca dos estudantes por uma rearticulação dos seus conhecimentos.

Com os dados obtidos e a análise de conteúdo foi possível identificar erros e incompreensões sobre o contexto, o conteúdo científico e a capacidade de produtividade de gêneros discursivos dentre os jovens estudantes, levando a uma retomada de assunto para sanar essas dúvidas. Os alunos se empenharam para realizar a primeira atividade desse gênero, e mesmo que com dificuldades podemos considerar válida a atividade aqui proposta para síntese dos conhecimentos, pois foi possível encontrar dificuldades que talvez não encontraríamos em uma pergunta direcionada.

O desfecho desse artigo ressalta a importância de trabalhar tanto a leitura quanto a escrita, além de tabelas e cálculos, de modo interdisciplinar e articulado, por proporcionar ao aluno maneiras diversas de compreender as ciências, de modo plural e heterogêneo, potencializando ainda outras habilidades não incentivadas no ensino de Química, como a poesia, a rima, o riso e as criatividades.

Para concluir, algumas questões e provocações podem nos conduzir a pensarmos estudos sobre estas articulações entre literatura e Química: Por que utilizar poemas nas aulas de Química? Como desenvolver uma sequência contextualizada que articule criatividade, poesia e Química? Como você, professor, tem se dedicado a leitura e a escrita? Que interesses (pedagógicos e sociais) devem 
ser levados em consideração ao propormos uma atividade lúdica que conecte literatura e ciências? 


\title{
The use of haikai in the discipline of chemistry - a creative way of uniting literature and science
}

\begin{abstract}
The difficulty with students' reading worries teachers from all disciplines and all leves of Elementary School, and it doesn't go unnoticed by Chemistry teachers, for such inconvenient affects directly in students' comprehension in chemistry content just as well as in developing citizens that aim social transformation. Haiku in Chemistry discipline presents as a possibility of articulating disciplines taken as separated, looking for working the content synthesis with the students view, promoting writing in a light way, although, full of meanings that have been analyzed in this paper. There are different ways to promote reading and writing in a classroom, and with this paper it's possible to observe that these two tools are fundamental to the process of teaching/learning, going from a contextualized Chemistry class and reaching poems that talk about Chemistry and awareness.
\end{abstract}

KEYWORDS: Reading. Haiku. Teaching. Chemistry. Criativity. 


\section{AGRADECIMENTOS}

Agradecemos aos sujeitos de pesquisa e a Universidade Tecnologia Federal do Paraná - Campus de Campo Mourão.

\section{NOTAS}

1. Segundo Bruno Latour (2000), a Ciência com letra maiúscula e no singular distancia a mesma de suas articulações sociais, políticas, econômicas e culturais, tornando-a algo mítico, "mascarado" e dissociado, tornando-a algo dogmático, muito próximo ao que vemos das práticas educativas na disciplina de Química, neste trabalho, diferente disso, buscaremos o que o autor pontua como ciências, no plural e em letras minúsculas, distanciando a disciplina de Química, da sua superioridade e dogmatização.

\section{REFERÊNCIAS}

BRASIL. LDB - Lei no 9394/96, de 20 de dezembro de 1996. Diário Oficial da União, Ministério de Educação e Cultura. Brasília, DF, 23 dez. 1996. Seção 1, p. 27833.

BRASIL. Medida Provisória no 746/2016, de 22 de setembro de 2016. Diário Oficial da União. Poder Executivo, Brasília, DF,23 set 2016. Seção 1, p. 1.

BRASIL. Instituto Nacional de Estudos e Pesquisas Educacionais - INEP. - Censo Escolar da Educação Básica - SAEB. Brasília-DF, 2017a. Disponível em: http://download.inep.gov.br/informacoes_estatisticas/sinopses_estatisticas/sino pses_educacao_basica/sinopse_estatistica_educacao_basica_2017.zip. Acesso em: 08 nov. 2018.

BRASIL. Lei 13.415, de 16 de fevereiro de 2017. Diário Oficial da União. Poder Legislativo. Brasília, DF,17 fev 2017b. Seção 1, p. 1.

BRASIL. Ministério da Educação. Secretaria de Educação Média e Tecnológica. Parâmetros Curriculares Nacionais do Ensino Médio: bases legais. Brasília: MEC/SEMT, 2000.

CALDEIRA A. M. S.; ZAIDAN S. Práxis Pedagógica: um desafio cotidiano. Revista Paidéia, Belo Horizonte, v.10, n. 14, p. 15-32, jan./jun. 2013.

FIOROTTI, D. A.; OLIVEIRA, J. G. Erenkon, a Literatura e os haicais. Boitatá, v. 22, p. 49-67, 2016.

FLÔR, C. C.; CASSIANI, S. O que dizem os estudos da linguagem na educação científica? Revista brasileira em pesquisa em educação em ciências, Belo Horizonte, v. 11, n. 2, p. 67-86, 2011. Disponível em: https://seer.ufmg.br/index.php/rbpec/article/view/2401. Acesso em: 04 nov. 2018. 
FRANCHETTI, Paulo. O haicai no Brasil. ALEA, v. 10, n. 2, p. 256-269, jul./dez. 2008. Disponível em:

https://www.researchgate.net/publication/262620652_O_Haicai_no_Brasil/fullte xt/039989400cf2f321f131b253/O-Haicai-no-Brasil.pdf Acesso em: 12 fev. 2012.

FRANCISCO JUNIOR, W. E. Estratégias de Leitura e Educação Química: Que Relações? Química Nova na Escola, v. 32, p. 220-226, 2010.

GIL, Antonio Carlos. Didática do ensino superior. São Paulo: Atlas, 2006.

KRIPPENDORFF, K. Metodologia de análisis de contenido: teoria e práctica. Barcelona, Ediciones Paidós, 1990.

LATOUR, BRUNO. Ciência em ação: como seguir cientistas e engenheiros sociedade afora. São Paulo: UNESP, 2000.

LÜDKE, M.; ANDRÉ, M. E. D. A.; Pesquisa em Educação: Abordagens Qualitativas. 2a Ed. Rio de Janeiro: E.P.U., 2014.

MARAFRON M. C.; MASSAGLI. S. R. O haicai de Paulo Leminski como recurso no ensino de literatura. In: 17 Jornada de Estudos Linguísticos e Literários, Marechal Candido FLRondon, 2014.

MAZZEU, L. T. B. A política de formação docente no brasil: fundamentos teóricos e epistemológicos. ANPEd, Caxambu, v. 32. p. 78-78 2008.

MOREIRA, I. C. M. Poesia na aula de ciência? A literatura poética e os possíveis usos didáticos. Disponível em:

http://www.sbfisica.org.br/fne/Vol3/Num1/a07.pdf. Acesso em: 02 jun. 2020.

SÁ, S. S. C.; SANTOS W.L.P. Licenciatura em Química: carência de professores, condições de trabalho e motivação pela carreira docente. 2011.Disponível em: http://www.nutes.ufrj.br/abrapec/viiienpec/resumos/R0544-1.pdf. Acesso em: 30 mai. 2020.

PARANÁ. Secretaria de Estado da Educação. Diretrizes Curriculares de Educação Básica Química. Curitiba: SEED, 2008. Disponível em:

http://www.educadores.diaadia.pr.gov.br/arquivos/File/diretrizes/dce_quim.pdf. Acesso em: 08 set. 2018.

PPP. Projeto Político-Pedagógico do Colégio Estadual Princesa Isabel - 2018.

PONTES, A. N.; SERRÃO, C. R. G.; FREITAS. C. K. A. O Ensino de Química no Nível Médio: Um Olhar a Respeito da Motivação. In: XIV Encontro Nacional de Ensino de Química, Curitiba, 2008. v. 1.

VASCONCELLOS, C. do S. Planejamento: projeto de ensino-aprendizagem e projeto político-pedagógico - elementos metodológicos para elaboração e realização. Cadernos Pedagógicos do Libertad, São Paulo, ed. 22, v. 1, 2012. 
OLIVA, A. D.; SANTOS, V. P. dos. Aprendizagem colaborativa e ativa no Ensino de Química. Cadernos PDE, Curitiba, v. 1, 2016.

TARTUCE, G. L. B. P.; NUNES, M. M. R.; ALMEIDA, P. C. A. Alunos do ensino médio e atratividade da carreira docente no Brasil. Cadernos de Pesquisa, v. 40, n. 140, p. 445-477, maio/ago. 2010.

TORRICELLI, E. Dificuldades de aprendizagem no Ensino de Química. (Tese de livre docência), Belo Horizonte, Universidade Federal de Minas Gerais. Faculdade de Educação, 2007.

WENZEL, J. S.; MARTINS, J. L. de C.; COLPO, C. C.; RIBEIRO, T. A. A prática da leitura no ensino de química: modos e finalidades de seu uso em sala de aula. ACTIO, Curitiba, v. 3, n. 2, p. 98-115, mai./ago. 2018.

Recebido: 27 fev. 2020

Aprovado: 01 jul. 2020

DOI: $10.3895 / a c t i o . v 5 n 3.11687$

Como citar:

PRICINOTTO, G.; LIMA, A. M. de.; FALKOWSKI, D. J. O uso de haicais no ensino de Química:

interdisciplinaridade e ludicidade na articulação entre Ciências e Literatura. ACTIO, Curitiba, v. 5, n. 3, p. 1 -

19, set./dez. 2020. Disponível em: <https://periodicos.utfpr.edu.br/actio>. Acesso em: XXX

Correspondência:

Gustavo Pricinotto

Rua Jussara, n. 95, Centro, Japurá, Paraná, Brasil.

Direito autoral: Este artigo está licenciado sob os termos da Licença Creative Commons-Atribuição 4.0

Internacional.

(c) (i) 